\title{
TD-DFT Investigation on the Electronic Spectra of Novel $N$-methylmaleimides Linked with Indolizine Ring System
}

\author{
Yasuhiro Shigemitsu $^{\mathrm{a}^{*}}$, Kaori Komiya ${ }^{\mathrm{b}}$, Naoko Mizuyama ${ }^{\mathrm{b}}$, Yoshinori Tominaga ${ }^{\mathrm{b}}$ \\ ${ }^{a}$ Industrial Technology Center of Nagasaki, 2-1303-8, Ikeda, Omura, Nagasaki 856-0026, Japan \\ ${ }^{b}$ Faculty of Environmental Studies, Nagasaki University, 1-14, Bunkyo-machi, Nagasaki 852-8521, Japan
}

\begin{abstract}
The major electronic absorption features in visible region were computationally investigated for a series of novel $\mathrm{N}$-methylmaleimide derivatives. The newly synthesized compounds through the reaction of indolizines with $N$-methylmaleimides exhibited their maxima ranging $587-634 \mathrm{~nm}$ in solution at room temperature. Time dependent density functional theory (TD-DFT) calculations were performed in order to elucidate their structure-color relationship, as well as to assess its performance using a variety of exchange-correlation (XC) functionals and basis sets. 4-(indolizin-3-yl)-1-methyl-2,5-dioxo-1H-pyrrole-3-carbonitrile (referred to $\mathbf{3 a}$ hereafter), a representative of the new compounds, was analyzed in detail on its intramolecular push-pull electronic structure. As a consequence of systematic evaluation of computational strategies for $\mathbf{3 a}$, we found that the theoretical $\lambda_{\max }$ obtained by PCM-TDDFT/6-31+G(d,p)//DFT/6-311G(2d,2p) level of theory, which was consistently employed throughout this study, has converged within $2 \mathrm{~nm}$ deviation from $\lambda_{\max }$ of the most elaborated level considered. Among some of the molecules with near-planarity structure, unusual discrepancies between the theoretical and the experimental $\lambda_{\max }$ were observed, which should be attributed to the well-known TD-DFT limitation to describe multi-configurational or charge transfer (CT) excitations.
\end{abstract}

Keywords: New maleimide derivatives; Indolizine; Electronic spectra; TD-DFT

\section{Introduction}

Fused or functionalized maleimides are synthetically useful intermediates for the preparation of polycyclic and fused pyridazine derivatives [1], also known as active dienophiles in Diels-Alder reactions or as 1,3-dipolar reagents [2]. Through the extensive study on ketene dithioacetals utilized for heterocyclic synthesis $[3,4]$, we have explored a wide utility of the functionalized maleimides which serve as active electrophilic reagents to afford fused pyridazine derivatives [5] and polymethine dyes [6-7]. The new dyes studied in this article comprise two key building-blocks; an electron-donating indolizine moiety and an electron-drawing maleimide ring. Indolizines, having peripheral $10 \pi$ conjugated electronic structure, has been extensively examined because of its wide range of potent applications such as biological activities [8] and a fluorescent probe [9] and also been experimentally and computationally examined for its electronic structure [10-13] and the NMR chemical shifts $[14,15]$. Maleimides, a counterpart building-block, have been also researched for medicinal purpose as a cross-linker unit to mediate biological functions in molecular level [16-17]. A parent maleimide (1H-pyrrole-2,5-dione) has been theoretically investigated in detail to characterize its electronic structure and the UV-Vis electronic spectra [18-20]. It is interesting to theoretically elucidate the synergetic effect on the electronic spectra of the new compounds presented, where the two electronically contrasting moieties are directly linked by a single $\mathrm{C}-\mathrm{C}$ bond; that is whether they work as a whole chromophic system or as independent subsystems.

TD-DFT [21] has been widely used in electronic transition energy predictions. TD-DFT shows good performance in the prediction of valence excitation energies for many molecules [22-23], with modest computational burden, its theoretical simplicity and independence from empirical parameters. TD-DFT is of universal use for small to medium sized dyes, with careful considerations to $\mathrm{XC}$ functional features and

\footnotetext{
*Corresponding author. Tel.: +81-957-52-1133

Fax: +81-957-52-1133

E-mail address: shige@tc.nagasaki.go.jp (Y.Shigemitsu)
} 
basis set selections. Owing to recent refinement of TD-DFT calculation strategy conducted by Perpête et al, excellent performance of TD-DFT $\lambda_{\max }$ (within $10 \mathrm{~nm}$ deviations from experimental $\lambda_{\max }$ ) have been reported for conjugated compounds such as indigo [24] and thioindigo dyes [25], anthraquinones [26-27] and coumarins [28], where linear- or multi-regression interpolation techniques are sometimes required to obtain quantitatively precise $\lambda_{\max }$ prediction within a few nm deviation. TD-DFT has been effectively applied also to analyze the complex electronic spectra of short-lived tautomeric species of 5,6-indolequinones [29-30]. On the other hand, some TD-DFT limitations have been reported in case such as multi configuration-nature excitations [31], intramolecular CT and Rydberg excitations which require asymptotic correction to the XC functionals for quantitative accuracy [32]. Several heteroatom-rich small molecules, polyaza-substituted benzene and polymethine dyes fail to have good agreements between experiment and theory using TD-DFT with a compact basis set $(6-31+G)$ [33]. As a typical case, TD-DFT excitation energy of cyanine dyes gave the systematic $0.3-0.4 \mathrm{eV}$ overestimation even including solvent effects [34], where the complicated TD-DFT limitations abovemensioned are involved [35-36]. Recent developments in the XC description [37] have not fully resolved these problematic cases.

The present work reports the newly prepared dyes bearing intramolecular push-pull systems and computationally investigated their intense electric absorption peaks in visible region, which is decisively responsible for their color appearance. In order to theoretically establish the structure-and-color relationship of the newly obtained molecules which have donor (indolizine) and acceptor (maleimide) units connected with single bond, we tried to find the optimal combination of DFT and TD-DFT parameters including basis sets, solvent effects and XC functionals.

\section{Synthesis and electronic spectra}

The newly synthesized compounds and the synthetic scheme are illustrated in Table 1 and Figure 1, respectively. Compound 1a reacted with indolizine 2a under refluxing in the presence of acetic acid in toluene to give a separate mixture of 4-cyano-indolizin-3-yl-1-methylmaleimide $\mathbf{3 a}$ and 4-cyan-3-indolizin-1-yl-1-methylmaleimide 4a, respectively. Reaction of 1a with other 2-substituted indolizines $\mathbf{2 b}$, 2c under the same reaction conditions afforded the corresponding mixture of 3-(2-substituted indolizin-3-yl)-1-methylmaleimides $3 \mathbf{b}, \quad 3 \mathbf{c} \quad$ and 3-(2-substituted indolizin-1-yl)-1-methylmaleimides $\mathbf{4 b}$, 4c. The methyl ester $\mathbf{1 b}$ reacted with 2-methylthioindolizine $\mathbf{2 b}$, yielding an inseparable mixture of $\mathbf{3 d}$ and $\mathbf{4 d}$. A series of 7-dimethylamino substituted indolizines $\mathbf{2 d - h}$ were also allowed to react with 1a, 1b, leading to the corresponding heterocycles $3 \mathbf{3 e}, 3 f, 4 e-4 h, 5 a, 5 b .6 a$ and $6 \mathbf{b}$ were obtained with the reaction $\mathbf{1 a}, \mathbf{1 b}$ and $\mathbf{2} \mathbf{j}$.

The UV/vis spectra were measured in ethanol or dimethylsulfoxide (DMSO) at room temperature. 4a-h showed their maxima in shorter wavelength than the corresponding 3a-h, owing to the different substitution position on the indolizine ring. As well-known, dialkylamino groups on aromatic or heteroaromatic compounds invoke a substantial bathochromic shift. The dialkylamino-substituted compounds $\mathbf{3 e}, \quad \mathbf{3 f}$ therefore showed a significant red shift in comparison with the corresponding non-dialkylamino-substituted dyes 3a, 3c. The first intense $\pi-\pi^{*}$ absorption peaks of the dialkylamino-substituted compounds $\mathbf{3 e - 3 h}, \mathbf{4 e - 4 h}$ were distributed around c.a. $600 \mathrm{~nm}$, in comparison with those of $550 \mathrm{~nm}$ of 3a-d. Among (3a-h, 4a-h), 3g showed the most bathochromic shift of which $\lambda_{\max }$ appears at $634 \mathrm{~nm}$. The di-substituted compounds $\mathbf{5 a}$, $5 \mathbf{b}$ exhibited the further mesomeric shifts with its $\lambda_{\max }$ at 681 and $729 \mathrm{~nm}$, respectively. In contrast, benzo-annulated indolizine derivatives $\mathbf{6 a}, \mathbf{6 b}$ yielded small hypsochromic shifts in comparison to the corresponding derivatives $\mathbf{3 c}, \mathbf{3 d}$, in spite of their extended $\pi$-conjugation system.

The details of synthesis and experimental data are given in the supplementary information.

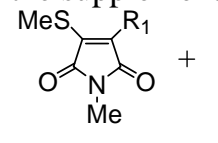

$\left(\mathbf{1} \mathbf{a}: \mathrm{R}_{1}=\mathrm{COOMe} \quad\left(\mathbf{2} \mathbf{a}: \mathrm{R}_{2}=\mathrm{H}, \mathbf{2} \mathbf{b}: \mathrm{R}_{2}=\mathrm{C}_{6} \mathrm{H}_{5}\right.\right.$, $\left.\left.\mathbf{1 b}: \mathrm{R}_{1}=\mathrm{CN}\right) \quad 2 \mathrm{c}: \mathrm{R}_{2}=\mathrm{SMe}\right)$

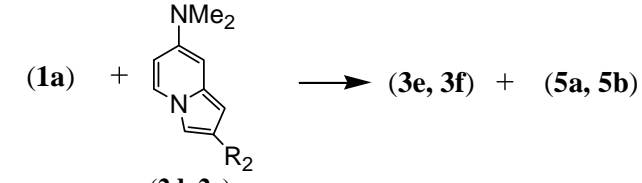<smiles>[14CH3]</smiles><smiles>[R2]c1cc2ccccn2c1</smiles><smiles>CN(C)C</smiles><smiles></smiles>

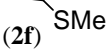<smiles>[R]c1cc2cc(N(C)C)ccn2c1[R]</smiles>

(2g,2h,2i)

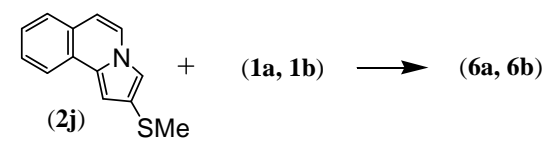

Figure 1. Schematic synthesis diagram of $\mathbf{3 a - 3 h}, \mathbf{4 a}-\mathbf{4 h}, \mathbf{5 a}, \mathbf{5 b}$ and $\mathbf{6 a}, \mathbf{6 b}$ 
Table 1 Recaptulatives of the newly synthesized compounds along with the key geometrical parameters $\left(r, \theta, r_{1}, r_{2}, \theta_{1}, \theta_{2}\right)$

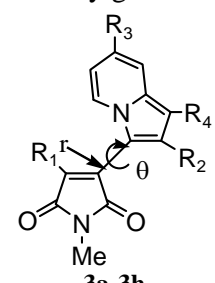

3a-3h

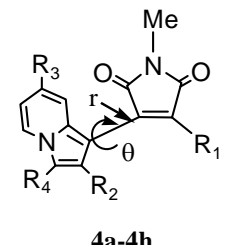

4a-4h
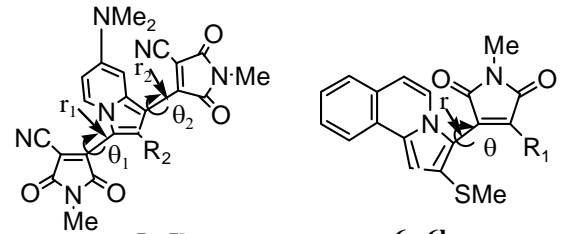

6a,6b

\begin{tabular}{ccccc}
\hline Entry & $\mathrm{R}_{1}$ & $\mathrm{R}_{2}$ & $\mathrm{R}_{3}$ & $\mathrm{R}_{4}$ \\
\hline 3a & $\mathrm{CN}$ & $\mathrm{H}$ & $\mathrm{H}$ & $\mathrm{H}$ \\
$\mathbf{3 b}$ & $\mathrm{CN}$ & $\mathrm{C}_{6} \mathrm{H}_{5}$ & $\mathrm{H}$ & $\mathrm{H}$ \\
$\mathbf{3 c}$ & $\mathrm{CN}$ & $\mathrm{SMe}$ & $\mathrm{H}$ & $\mathrm{H}$ \\
$\mathbf{3 d}$ & $\mathrm{COOMe}$ & $\mathrm{SMe}$ & $\mathrm{H}$ & $\mathrm{H}$ \\
$\mathbf{3 e}$ & $\mathrm{CN}$ & $\mathrm{H}$ & $\mathrm{NMe}_{2}$ & $\mathrm{H}$ \\
$\mathbf{3 f}$ & $\mathrm{CN}$ & $\mathrm{SMe}$ & $\mathrm{NMe}_{2}$ & $\mathrm{H}$ \\
$\mathbf{3 g}$ & $\mathrm{COOMe}$ & $\mathrm{SMe}$ & $\mathrm{NMe}_{2}$ & $\mathrm{CN}$ \\
$\mathbf{3 h}$ & $\mathrm{CN}$ & $\mathrm{SMe}$ & $\mathrm{NMe}_{2}$ & $\mathrm{CN}$ \\
$\mathbf{4 a}$ & $\mathrm{CN}$ & $\mathrm{H}$ & $\mathrm{H}$ & $\mathrm{H}$ \\
$\mathbf{4 b}$ & $\mathrm{CN}$ & $\mathrm{C}_{6} \mathrm{H}_{5}$ & $\mathrm{H}$ & $\mathrm{H}$ \\
$\mathbf{4 c}$ & $\mathrm{CN}$ & $\mathrm{SMe}$ & $\mathrm{H}$ & $\mathrm{H}$ \\
$\mathbf{4 d}$ & $\mathrm{COOMe}$ & $\mathrm{SMe}$ & $\mathrm{H}$ & $\mathrm{H}$ \\
$\mathbf{4 e}$ & $\mathrm{CN}$ & $\mathrm{H}$ & $\mathrm{NMe}_{2}$ & $\mathrm{COOEt}$ \\
$\mathbf{4 f}$ & $\mathrm{CN}$ & $\mathrm{SMe}$ & $\mathrm{NMe}_{2}$ & $\mathrm{COOEt}$ \\
$\mathbf{4 g}$ & $\mathrm{COOMe}$ & $\mathrm{SMe}$ & $\mathrm{NMe}_{2}$ & $\mathrm{COOEt}$ \\
$\mathbf{4 h}$ & $\mathrm{CN}$ & $\mathrm{SMe}$ & $\mathrm{NMe}_{2}$ & $\mathrm{CN}$ \\
$\mathbf{5 a}$ & - & $\mathrm{H}$ & - & - \\
$\mathbf{5 b}$ & - & $\mathrm{SMe}$ & - & - \\
$\mathbf{6 a}$ & $\mathrm{COOMe}$ & - & - & - \\
$\mathbf{6 b}$ & $\mathrm{CN}$ & - & - & - \\
\hline & & & &
\end{tabular}

\section{Computational details}

The calculations were performed by means of GAUSSIAN03 [38] suite of program. Graphical representations of orbitals and of subtraction electron density were created by ChemCraft Software [39].

The ground-state geometry optimizations were carried out based on DFT using B3LYP hybrid functional combined with a series of Pople's standard basis sets (6-31G, 6-31G(d,p), 6-311G(d,p), 6-311G(2d,2p), $6-31+G(d, p), \quad 6-311++G(d, p), \quad 6-311++G(2 d, 2 p)$, and $6-311++G(3 d f, 3 p d))$ using the default convergence criterion on force and displacement, aiming to find a well-balanced level of theory between computational burden and accuracy.

In TD-DFT calculations for the DFT-optimized geometries, various XC-functionals were employed; generalized gradient approximation (GGA) (BLYP), meta-GGA(VSXC), hybrid type (B3PW91, B3LYP, O3LYP, PBE0, MPW1PW91) and Handy's asymptotically corrected functional HCTH/407 to obtain the vertical excitation energies and their associated oscillator strengths (f).

In both step of DFT and TD-DFT calculations, solvent effects of ethanol and DMSO were included using the Polarizable Continuum Model (PCM). The default Gaussian03 PCM implementation (non-equilibrium formulation) is suitably designed to predict UV/vis spectrum described within the vertical transition scheme, where solvent polarization responds to the change of electronic distribution of the excited state molecules with the molecular orientation fixed during electronic transition [40]. The optimized geometries were validated with vibrational frequency analysis for the representative compounds (3a, $\mathbf{3 b}, \mathbf{4 a}, \mathbf{4 b})$, while the checks for $(\mathbf{5 a}, \mathbf{5 b}, \mathbf{6 a}, \mathbf{6 b})$ were not done because of our computational limitations.

\section{Results and discussion}

4.1 Compound 3a: assessment of TD-DFT methodology and the electronic structure details

As a prototypical case study of the molecules in question, we assessed the convergence of TD-DFT $\lambda_{\text {max }}$ for 3a. It is well known that combinations of XC functionals and basis sets critically affect on TD-DFT excitation energies. First, we assessed the DFT steps, i.e., the influence of optimized geometries and basis sets on the predicted $S_{0}-S_{1}$ transition energy. A standard B3LYP hybrid functional was consistently employed for both geometry optimizations and TD-DFT calculations. Two key geometrical parameters, the length of the single bond connecting two moieties ( $\mathrm{r}$ $=1.402 \AA)$ and the inter-ring torsion angle $\left(\theta=27.3^{\circ}\right)$, are defined in Table 1 . These two parameters are consistently referred to hereafter in the following series of compounds (3b-h, 4a-h, 5a-b, 6a-b). The bond length $r$, appreciably shorter than the standard single $\mathrm{C}-\mathrm{C}$ bond length by c.a. $0.1 \AA$, indicates moderate electronic resonance between the two moieties. Table 2 shows the evolution of $\lambda_{\max }$ as a function of basis sets used in both geometry optimizations and TD-DFT calculations. As for the basis set effect on the geometry optimizations, we notice the uniform role of polarization, valence-splitting, and diffuse functions, being irrelevant to the basis set choice in TD-DFT calculations. The $\lambda_{\max }$ obtained $6-31 \mathrm{G}(\mathrm{d}, \mathrm{p})$ geometry gave $16 \mathrm{~nm}$ blue shift in comparison to that of 6-31G. The valence-triple-zeta basis set $6-311 G(d, p)$ instead of valence-double basis 6-31G(d,p) yielded $3 \mathrm{~nm}$ blue shift. $6-31+G(d, p)$ basis set, augmented by single 
diffuse function, shifted $\lambda_{\max }$ inversely, giving $3 \mathrm{~nm}$ red shift relative to that of $6-31 G(d, p)$. The blue-shift effect (polarization, valence-splitting) and red-shift effect (diffuse) were also observed in the case of thioindio dyes [25]. The most expensive basis set 6-311++G(3df,3dp), constructed by an extra augmentation of polarization function to $6-311++G(2 d, 2 p)$, gave hardly affect on $\lambda_{\max }$, within 1 $\mathrm{nm}$ deviation. Second, we focus on the basis set effect used in TD-DFT calculations. TD-DFT basis set improvement going from 6-31G to 6-311++G(3df,3dp) gave $15 \mathrm{~nm}$ red shift, uniformly seen for all the optimized geometries. In detail, 6-311G(2d,2p) gave only $2 \mathrm{~nm}$ red shift from 6-31G, an indication of the minor influence of polarization and double/triple zeta splitting. On the other hand, 6-31+G(d) gave considerable red shift of $12 \mathrm{~nm}$ in comparison with 6-31G, which means critical role of diffuse function. These trends were also found in the case of diazonium ion with minor contribution of polarization and diffuse enhancement [41], anthraquinone derivatives with polarization and valence-splitting [26], but are sharp contrast to the case of thioindigo dyes, where the three type of basis set enhancements (polarization, valence-splitting, and diffuse function) monotonically gave substantial red-shift effects [25]. The $\lambda_{\max }$ finally converged to $514 \mathrm{~nm}$, the most expensive result in this study using PCM-TD-DFT(B3LYP)/6-311++G(3df,3dp)//PCM-DF T(B3LYP)/6-311++G(3df,3dp). The $\lambda_{\max }$ gap between PCM-TD-DFT(B3LYP)/6-31+G(d,p)//PCM-DFT(B3L YP)/6-311G(2d,2p) and the most exhaustive calculation above-mentioned is as small as $2 \mathrm{~nm}$. We therefore can safely use PCM-TD-DFT(B3LYP)/6-31+G(d,p)//PCM-DFT(B3L YP)/6-311G(2d,2p) as a balanced scheme between accuracy and computational burden. Third, we focus on the $\mathrm{XC}$ functional influence. $\lambda_{\max }$ minor dependencies on the selected XC-functionals were known for geometry optimization [25]; theoretical $\lambda_{\max }$ does not severely depend on the XC-functionals within $10 \mathrm{~nm}$ deviations using O3LYP, B3LYP, PBE0. Therefore we focused on the influence of XC-functionals for TD-DFT calculations, consistently using the optimized geometry obtained by DFT(B3LYP)/6-311G(2d,2p). The results are summarized in Table 3 . In using hybrid functionals, the mixing weight of exact (Hartree-Fock) exchange critically affects the calculated $\lambda_{\max }$ [25]; O3LYP with $11.67 \%$, B3LYP with 20\%, PBE0 with 25\%, respectively. The calculated $\lambda_{\max }$ with PCM is shifted hypsochromically as the mixing percentage rises; 523 nm (O3LYP), $521 \mathrm{~nm}$ (B3LYP), 500 nm (PBE0). Other functionals, GGA (BLYP), meta-GGA (VSXC) and asymptotically corrected functional (HCTH/407) predicted fairly large red-shifted $\lambda_{\max }, 556,532$ and 549 $\mathrm{nm}$, respectively, with better accord to the experimental $\lambda_{\max } 551 \mathrm{~nm}$. Slight influence of the correlation term to $\lambda_{\max }$ was found with the gap between B3LYP and B3PW91 being only $3 \mathrm{~nm}$ and MPW1PW91 being within $1 \mathrm{~nm}$. Finally, we examined the solvent effect using PCM scheme, as listed in Table 3 . We note the negligibly minor role of solvent effect in geometry optimization; calculated $\lambda_{\max }$ consistently remained unchanged within $2 \mathrm{~nm}$ for all XC-functional employed. The solvent effect can be categorized into two components; geometrical fluctuation (indirect effect) and electronic perturbation (direct effect). The molecules in question with moderate intramolecular donor-acceptor system may show these two effects independently. In reality, the geometrical perturbation gave little effects. Vacuo-TD-DFT(B3LYP)6-31+G//Vacuo-DFT(B3LYP) $6-311 G(2 d, 2 p)$ gave $475 \mathrm{~nm}$ with a considerable $\lambda_{\max }$ gap by $36 \mathrm{~nm}$ in comparison with PCM-TD-DFT(B3LTP)6-31+G//Vacuo-DFT(B3LYP)6$311 G(2 d, 2 p)$ (not in the Tables), which means that direct electronic perturbation play a dominant role in solvent effect. In our previous TD-DFT study for another series of maleimide derivatives [6-7], geometry optimizations including solvent effects were not performed. This is qualitatively rationalized including only direct electronic effect.

In further details about the electronic structure, we characterized the low-lying five singlet excited states within the current TD-DFT scheme as in Table 4. The first and second peaks originate from the $\pi-\pi *$ intramoleular CT transitions from indolizine ring to maleimide moiety. The first intense peak, dominantly describable with HOMO-LUMO excitation, has large $\mathrm{f}$ of 0.38 . The HOMO is mainly located on indolizine ring whereas the LUMO is on maleimide ring, depicted in Figure 2. $\mathrm{S}_{0^{-}}>\mathrm{S}_{1}$ (HOMO->LUMO) excitation therefore leads to intramolecular CT from indolizine to maleimide moiety, as illustrated in Figure 3 where the electron density increases (depicted by light gray surfaces) mainly in the maleimide moiety and decreases (by dark gray surfaces ) in the indolizine moiety. The second transition originates from HOMO-1(mainly distributed on indlizine ring) to LUMO with moderate $\mathrm{f}$ of 0.037. The third, fourth and fifth excited states have in common $\pi-\pi *$ local excitation (LE) character. The third LE occurs within maleimide moiety from HOMO-2 with $\sigma$-character to LUMO with $\pi$-character with small $\mathrm{f}$ of 0.003 . The fourth $\pi-\pi * \mathrm{LE}$ occur within indolizine ring. The fifth excitation occurs within maleimide ring with moderate $\mathrm{f}$ of 0.193 . Experimentally, the first $\pi-\pi *(\mathrm{CT})$ is ascribed to the first intense visible band and the fifth transition to the second band. The second to the fourth transition with small $\mathrm{f}$ is thought to be overlapped with the two intense bands.

In aiming for further investigation on the UV/vis 
spectrum features, we carried out TD-DFT calculations of the two building-blocks; maleimide and indolizine listed in Table 5. As for maleimide, the bond length deviations between our DFT predictions and the $\pi$-CASSCF results by Climent et al [20] are negligibly small, less than $0.01 \AA$ even with the largest deviation for the carbonyl $\mathrm{C}=\mathrm{O}$. The five occupied orbitals comprise two n-orbitals and three $\pi$-orbitals whereas the lowest five unoccupied orbitals are composed of two $\pi$-orbitals and three Rydberg-like diffuse orbitals. These diffuse orbitals critically affect the excitation energies computed. We observed the state flipping between $1^{1} \mathrm{~A}_{2}\left(\mathrm{n}-\pi^{*}\right)$ and $1^{1} \mathrm{~B}_{2}\left(\pi-\pi^{*}\right)$. Our TD-DFT calculations had good agreements with the MS-CASPT2 results [20] for the $\pi-\pi^{*}$ transition energies within $0.1 \mathrm{eV}$ deviations, however showed poor agreements for $n-\pi^{*}$ transition with more than $1 \mathrm{eV}$ deviation from the MS-CASPT2 results. Such large discrepancies in $n-\pi^{*}$ excitation energies using TD-DFT were reported elsewhere by Lüthi [42] et al and Tozer \& Handy [43]. Turning to indolizine, the four occupied near-frontier MOs and the three unoccupied MOs have all $\pi$-character, in exception of LUMO+2 with $\sigma$-character. The first, second and fourth excited states are described by $\pi-\pi^{*}$ transition among (L-1, L, L+1, $\mathrm{H}-1, \mathrm{H})$ and the third transition described by $\pi-\sigma^{*}$ transition. A good agreement was obtained between TD-DFT and experiment with $0.04 \mathrm{eV}$ gap for the lowest excitation energy. The observed broad band ranging from $4.30-4.53 \mathrm{eV}$ is assigned to the second to the fourth calculated peaks with small $\mathrm{f}$. The fifth theoretical peak would be assigned to the third intense band observed, within the present level of theory.

By inspection of the MO correlation diagram in the near-frontier levels of $\mathbf{3 a}$ as depicted in Figure 4, the HOMO and the LUMO are constructed as a mixing of the HOMO and the LUMO of maleimide and indolizine from the elementary viewpoint of orbital interactions. The LUMO is far stabilized than the HOMO, which lead to the gap narrowing and considerable bathochromic shift in comparison with the parent compounds, indicating strong intramolecular CT between the two moieties. The $\phi_{60}, \phi_{65}, \phi_{66}$ and $\phi_{68}$ orbitals are generated from the orbital mixing of the parent molecules; $\phi_{61}, \phi_{62}, \phi_{63}$ dominantly originate from the maleimide MOs and $\phi_{64}$ and $\phi_{67}$ from indolizine MOs, respectively.

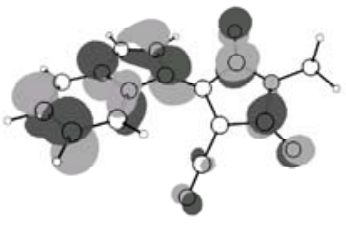

LUMO+2 : $\pi$ (indolizine)

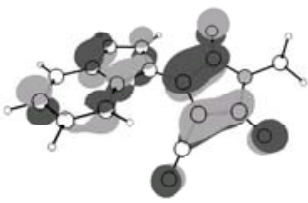

LUMO : $\pi$ (maleimide)

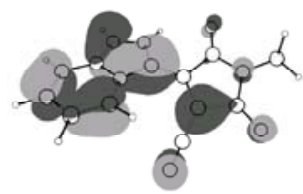

HOMO : $\pi$ (indolizine)

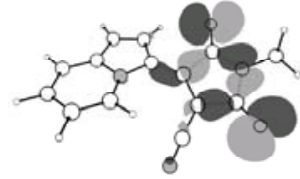

HOMO-2 : $\sigma$ (maleimide)

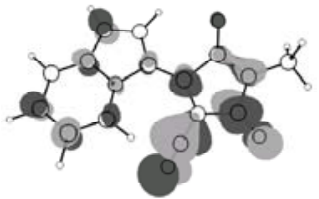

LUMO+3 : $\pi$ (maleimide)

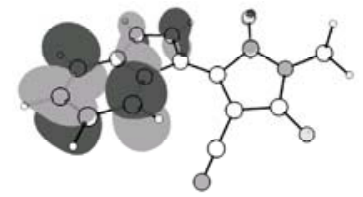

LUMO+1: $\pi$ (indolizine)

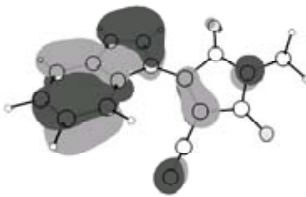

HOMO-1 : $\pi$ (indolizine)

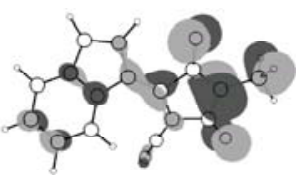

HOMO-3 : $\pi$ (maleimide)
Figure 2 Near-frontier molecular orbitals of $3 a$

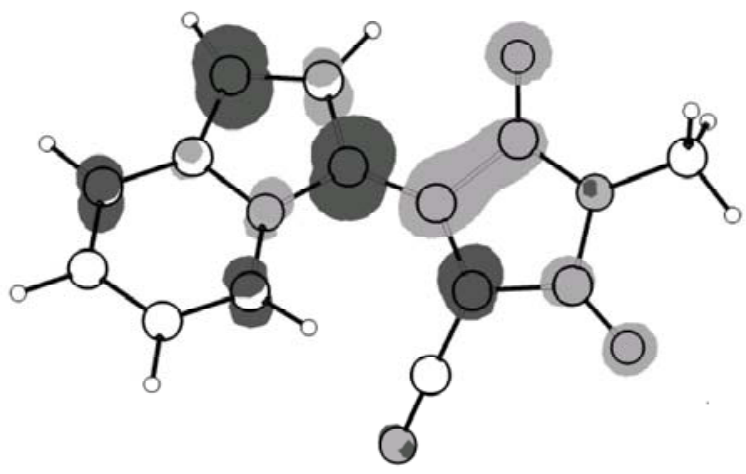

Figure 3. Square subtraction density distrubution from HOMO to LUMO of 3a 
maleimide

$3 a$

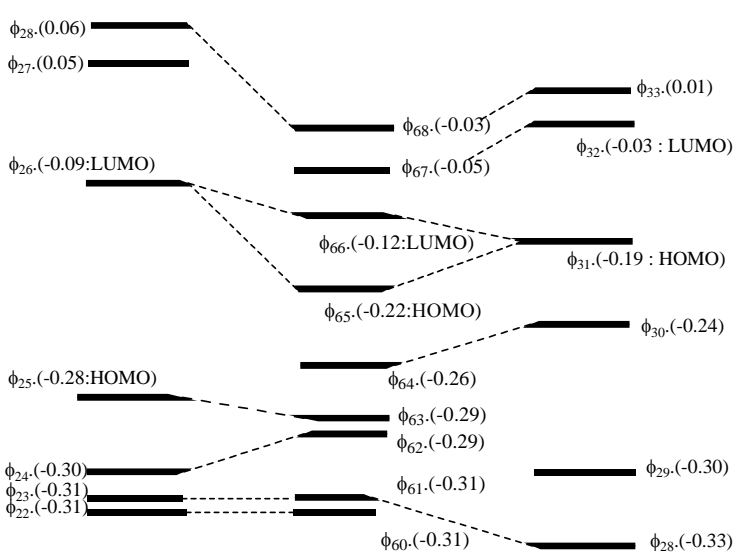

Figure 4. MO correlation dyagramof 3a through the interaction between the nearfrontier MOs of maleimide and indolizine. Orbital energies (in a.u.) calculated using PCM(Ethanol)-TD-DFT(B3LYP)/6-311G(2d.2p).

Table $2 \lambda \max$ (in nm) dependence of $3 a$ on the basis sets used for geometry optimization (DFT) and TD-DFT

\begin{tabular}{|c|c|c|c|c|c|c|c|c|}
\hline & \multirow[b]{2}{*}{ 6-31G } & \multicolumn{7}{|c|}{ Geometry basis set (DFT) } \\
\hline & & $\begin{array}{l}6-31 \\
\mathrm{G}(\mathrm{d}, \mathrm{p}) \\
\end{array}$ & $\begin{array}{l}6-311 \\
G(d, p) \\
\end{array}$ & $\begin{array}{l}6-311 \\
\mathrm{G}(2 \mathrm{~d}, 2 \mathrm{p}) \\
\end{array}$ & $\begin{array}{l}\begin{array}{l}6-31+ \\
\mathrm{G}(\mathrm{d}, \mathrm{p})\end{array} \\
\end{array}$ & $\begin{array}{l}\begin{array}{l}6-311++ \\
\mathrm{G}(\mathrm{d}, \mathrm{p})\end{array} \\
\end{array}$ & $\begin{array}{l}6-3-311++ \\
\mathrm{G}(2 \mathrm{~d}, 2 \mathrm{p}) \\
\end{array}$ & $\begin{array}{ll}6-311+++ \\
\text { G(3df,3dp) } \\
\end{array}$ \\
\hline \multicolumn{9}{|l|}{ TD-DFT Basis set } \\
\hline 6-31G & 520 & 505 & 502 & 499 & 508 & 503 & 501 & 500 \\
\hline 6-311G(2d,2p) & 523 & 507 & 504 & 501 & 510 & 505 & 503 & 502 \\
\hline $6-31+G(d)$ & 535 & 519 & 515 & 512 & 521 & 516 & 514 & 513 \\
\hline $6-31+G(d, p)$ & 535 & 519 & 515 & 512 & 522 & 516 & 514 & 513 \\
\hline $6-311++\mathrm{G}(2 \mathrm{~d}, 2 \mathrm{p})$ & 536 & 520 & 516 & 513 & 522 & 517 & 515 & 514 \\
\hline $6-311++\mathrm{G}(3 \mathrm{df}, 3 \mathrm{dp})$ & ) 535 & 519 & 516 & 512 & 522 & 517 & 514 & 514 \\
\hline
\end{tabular}

All DFT and TD-DFT calulations using the PCM option with built-in Ethanol's dielectronic constant (24.55)

Table 3 XC-functional effects on the calculated $\lambda \max ($ in $\mathrm{nm}$ )

\begin{tabular}{lcc}
\hline \multirow{2}{*}{ XC functionals } & \multicolumn{2}{c}{ Geometry } \\
\cline { 2 - 3 } & non-PCM $^{\mathrm{a}}$ & PCM $^{\mathrm{b}}$ \\
\hline BLYP & 558 & 556 \\
VSXC & 534 & 532 \\
O3LYP & 523 & 523 \\
B3LYP & 511 & 512 \\
B3PW91 & 508 & 509 \\
PBE0 & 499 & 500 \\
MPW1PW91 & 499 & 501 \\
HCTH/407 & 550 & 549 \\
\hline
\end{tabular}

All TD-DFT calculations using PCM(Ethanol)-B3LYP/6-31+G(d,p)

(a) Geometry optimized using vacuo-DFT(B3LYP)/6-311G(2d,2p)

(b) Geometry optimized using PCM(Ethanol)-DFT(B3LYP)/6-311G(2d,2p)

\begin{tabular}{|c|c|c|c|c|c|}
\hline \multirow{2}{*}{ state } & \multicolumn{3}{|c|}{ TDDFT(B3LYP)/6-31+G(d,p)//DFT(B3LYP)/6-311G(2d,2p) } & \multicolumn{2}{|c|}{ expl. } \\
\hline & main config. & $\lambda \max (\mathrm{nm})$ & $\begin{array}{l}\text { oscillator } \\
\text { strength }\end{array}$ & $\lambda \max (\mathrm{nm})$ & $\log \varepsilon$ \\
\hline $1 \mathrm{CT}: \pi-\pi^{*}$ & $\mathrm{H}->\mathrm{L}: 0.61$ & 512 & 0.375 & 551 & 4.39 \\
\hline $2 \mathrm{CT}: \pi-\pi^{*}$ & $\mathrm{H}-1>\mathrm{L}: 0.67$ & 383 & 0.037 & & \\
\hline $1 \mathrm{LE}: \sigma-\pi^{*}$ & H-2->L:0.65 & 345 & 0.003 & & \\
\hline $2 \mathrm{LE}: \pi-\pi^{*}$ & $\mathrm{H}->\mathrm{L}+1: 0.64$ & 319 & 0.022 & & \\
\hline $3 \mathrm{LE}: \pi-\pi^{*}$ & $\mathrm{H}-3>\mathrm{L}: 0.60$ & 301 & 0.193 & 293 & 3.94 \\
\hline
\end{tabular}

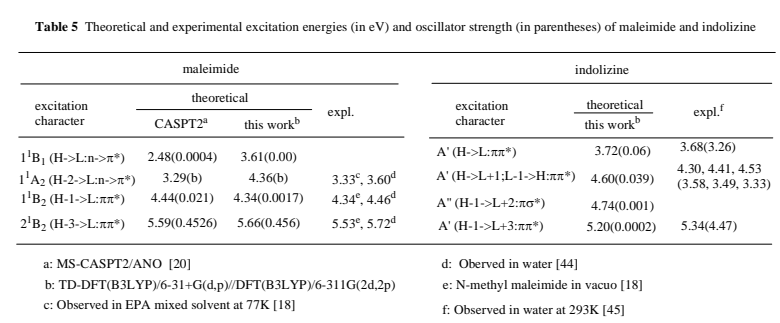

\subsection{Substituted maleimides $\mathbf{3} \boldsymbol{b}-\mathbf{h}, \mathbf{4} \boldsymbol{a}-\boldsymbol{h}, \mathbf{5} \boldsymbol{a}-\boldsymbol{b}$ and $\mathbf{6} \boldsymbol{a}-\boldsymbol{b}$}

Following the assessment in the previous subsection, we consistently applied PCM-TD-DFT/6-31+G(d)//PCM-DFT(B3LYP)/6-311G $(2 \mathrm{~d}, 2 \mathrm{p})$ to the remaining molecules.

The inter-ring torsional angles $\theta$ varied from 15 to 50 degree, with the compromise between steric hinderance of the two rings and dialkylamino group's $\pi$-conjugation extension effect which facilitates coplanarity restoration. 3e has the smallest $\theta$ among $\mathbf{3 b}-\mathbf{h}$, which indicates that the electronic resonance of 3e between dialkylamino group and $\pi$-conjugate system is the strongest among the compounds. The inter-ring bond $\mathrm{r}$ is therefore appreciably shortened for $3 \mathbf{e}$. In contrast, $r$ and $\theta$ of $\mathbf{3 f}, \mathbf{3 g}$, $\mathbf{3 h}$ indicate the substantially hindered structure from coplanarity, which means the resonance between the dialkylamino group and the whole system is weakened owing to steric repulsion. Table 6 contains the theoretical first peak positions of 3b-h along with the experimental $\lambda_{\max }$. The computed peaks considered the solvent effects with PCM option in both geometry optimization and the TD-DFT steps to be consistent with the UV/vis measurement. The theoretical peaks computed were diverse and seemed to be non-systematic. In our previous study [6-7], a local density functional (SVWN) and a pure GGA functional (BPW91) outperformed a standard hybrid B3LYP functional which predicted severely shorter $\lambda_{\max }$ than that of SVWN and BPW91. In the present study, qualitatively bathochromic shifts were computed in the order PBE0, MPW91PW91<B3LYP, B3PW91<O3LYP. PBE0 and MPWP1PW91 predicted closely theoretical peaks for 3b-d, however failed to have good agreements for $3 \mathbf{e}$ and $\mathbf{3 f}$ bearing dialkylamino group 
on indolizine ring. The hybrid functionals B3PW91, B3LYP, O3LYP gave underevaluated peaks in this order, with the peaks being blue-shifted proportional to the mixing ratio of an exact exchange term, as in the case of 3a. The deviations are not due to the indirect $\mathrm{XC}$-functional influence used geometry optimizations but to the direct influence in TD-DFT, in line with the minor influence of XC-functional used in geometry optimization [25]. Using the other functionals, the amplitude of $\lambda_{\max }$ displacement is severely large. The VSXC- and HCTH-predicated peaks of $\mathbf{3 g}$ showed large deviations of c.a. $100 \mathrm{~nm}$ from the observed peak. The transition is mainly describable by HOMO-LUMO excitation as in the case of $\mathbf{3 a}$. As the molecules distort from planarity, the mixed complex excitations such as HOMO-1 to LUMO or HOMO to LUMO+1 arise. The compounds 3e, 3f, 3g, 3h, with their peaks over $600 \mathrm{~nm}$, clearly possess its higher HOMO level than non-substituted $\mathbf{3 b}$-d, which means the bathochromic shifts are qualitatively explainable by the HOMO destabilization. As for $\mathbf{3 e}$, distinctively, the calculated LUMO level is spuriously destabilized, leading to unusually large discrepancy between theory and experiment, regardless of the XC-functional type employed. The reason for this error is probably because of the existent XC functionals which fails to adequately describe an intramolecular CT excitation. This is also indicated by the small twist angle of $\mathbf{3 a}$, 3e, 3f which favor the intramolecular CT, as shown in Table 7. Other molecules with large twist angle showed good $\lambda_{\max }$ agreement between TD-DFT and experiment owing to efficient charge separation between the two moieties.

As for $\mathbf{4 a - h}$, the theoretical first peak positions are listed in Table 6 along with the experimental ones. The overall tendencies are closely similar to $\mathbf{3 b} \mathbf{b}-\mathbf{h}$. The theoretical peaks were overevaluated for $\mathbf{4 f}, \mathbf{4 g}, \mathbf{4 h}$, with all the XC functionals, especially using VSXC and HCTH functionals by more than $100 \mathrm{~nm}$ deviations from the experimental $\lambda_{\max }$. In a series of hybrid functionals, B3PW91 gave the best results; O3LYP- $\lambda_{\max }$ appeared in longer wavelength region by c.a. 20-40 nm than those of B3PW91, with an intermediate of B3LYP- $\lambda_{\max }$. PBE0 and MPW1PW91 gave blue-shifted $\lambda_{\text {max }}$ than B3PW91- $\lambda_{\max }$ as a whole. As shown in Table 7 , $4 \mathbf{e}$ has the smallest key bond length and a flat structure among them and showed a substantially large deviation between TD-DFT and experimental $\lambda_{\max }$. The larger bathochromic shifts of $\mathbf{4 e - h}$ relative to $\mathbf{4 a - d}$ are also explainable by the HOMO destabilization.

TD-DFT $\lambda_{\max }$ of $\mathbf{5 a}, \mathbf{5 b}, \mathbf{6 a}, \mathbf{6} \mathbf{b}$ are summarized in Table 8. The agreements between theory and experiment are excellent using B3PW91, B3LYP, PBE0 and MPW1PW91. For instance, B3PW91 gave an almost perfect agreement with experimental $\lambda_{\max }$ in case of 5a, 6a. O3LYP, BLYP, VSXC, HCTH, in contrast, gave longer wavelengths than experimental $\lambda_{\text {max }}$. Peculiarly in case of $\mathbf{5 b}$, these four functionals gave surprisingly more than $100 \mathrm{~nm}$ bathochromic deviations. 5b has a complicated electronic structure of which electronic spectra exhibited minor peaks (864, 803 and $701 \mathrm{~nm}$ ) associated with the main peak (729 $\mathrm{nm}$ ) having non-negligible magnitude of absorbance. Thsese splittings are also rationalized by the smaller $\mathrm{f}$ of the main peak of $\mathbf{5 b}$, decreasing from 0.5114 (5a) to 0.3050 (5b). The key geometrical parameters $\left(r_{1}, r_{2}, \theta_{1}\right.$, $\theta_{2}$ ), designated in Table 1 , explain the degree of electronic resonance in the molecules. The steric repulsion between the methylthio group and the relevant ring part forces $\mathbf{5 a}$ to be a twisted form, as indicated by $\left(\theta_{1}, \theta_{2}\right)$ in Table 9 . The two key inter-ring C-C bond lengths $\left(\mathrm{r}_{1}, \mathrm{r}_{2}\right)$ are elongated for $\mathbf{5 b}$ than $\mathbf{5 a}$, indicating weakened intramolecular $\pi$-conjugation. The bathochromic shift of $\mathbf{5 a}$ relative to $\mathbf{5 b}$ is also explainable by the HOMO destabilization. In case of $\mathbf{6 a}$ and $\mathbf{6 b}$, the fictitious first theoretical peaks with quite small f (less than 0.1) were predicted in longer wavelength region than the observed first peak positions. This reflects the complicated electronic structures as a result of the introduction of a $\pi$-extended isoquinoline moiety.

\begin{tabular}{|c|c|c|c|c|c|c|c|c|c|}
\hline & BLYP & vsxc & ОЗLYP & B3LYP & B3PW91 & PBE0 & MPW1PW91 & НСТн $/ 407$ & Expl \\
\hline $3 \mathrm{~b}^{*}$ & 644 & 614 & 576 & 557 & 553 & 540 & 540 & 630 & 578 \\
\hline $3 c$ & 761 & 673 & 610 & 571 & 568 & 552 & 552 & 745 & 554 \\
\hline $3 d$ & 728 & 667 & 613 & 585 & 581 & 564 & 564 & 713 & 561 \\
\hline $3 \mathrm{e}^{*}$ & 572 & 547 & 539 & 527 & 525 & 517 & 517 & 566 & 601 \\
\hline $3 f^{*}$ & 656 & 614 & 594 & 580 & 578 & 568 & 568 & 643 & 627 \\
\hline $3 \mathrm{~g}^{*}$ & 758 & 729 & 680 & 646 & 644 & 622 & 622 & 750 & 634 \\
\hline $3 \mathbf{h}$ & 725 & 665 & 622 & 599 & 598 & 583 & 582 & 707 & 627 \\
\hline $4 a^{*}$ & 538 & 515 & 509 & 500 & 497 & 489 & 489 & 531 & 533 \\
\hline $4 b$ & 618 & 591 & 565 & 550 & 545 & 533 & 533 & 608 & 541 \\
\hline $4 c^{*}$ & 761 & 673 & 610 & 571 & 568 & 552 & 552 & 745 & 538 \\
\hline $4 d$ & 675 & 627 & 590 & 563 & 559 & 541 & 541 & 662 & 561 \\
\hline $4 e^{*}$ & 635 & 604 & 576 & 554 & 553 & 538 & 538 & 626 & 587 \\
\hline $4 f^{*}$ & 831 & 787 & 710 & 663 & 661 & 633 & 632 & 814 & 618 \\
\hline $4 \mathrm{~g}$ & 843 & 795 & 717 & 667 & 664 & 634 & 634 & 826 & 605 \\
\hline $4 \mathrm{~h}^{*}$ & 809 & 767 & 692 & 646 & 644 & 617 & 616 & 792 & 610 \\
\hline
\end{tabular}

源

(*) using PCM (DMSO); others using PCM (Ethanol). 
Table 7 Key geometrical parameters $\left(\mathrm{r}^{\mathrm{a}}, \theta^{\mathrm{b}}\right)$, HOMO, LUMO energy levels $(3 \mathbf{b}-\mathbf{h})^{\mathrm{c}},(\mathbf{4 a - h})^{\mathrm{c}}$

\begin{tabular}{|c|c|c|c|c|}
\hline & $\mathrm{r}$ & $\theta$ & HOMO (a.u.) & LUMO (a.u.) \\
\hline $3 \mathbf{b}^{*}$ & 1.411 & 41.5 & -0.217 & -0.123 \\
\hline $3 c$ & 1.416 & 46.8 & -0.218 & -0.125 \\
\hline 3d & 1.425 & 49.8 & -0.212 & -0.119 \\
\hline $3 \mathrm{e}^{*}$ & 1.386 & 14.9 & -0.201 & -0.108 \\
\hline $3 f^{*}$ & 1.400 & 29.0 & -0.200 & -0.115 \\
\hline $3 g^{*}$ & 1.428 & 46.3 & -0.204 & -0.123 \\
\hline $3 \mathbf{h}$ & 1.407 & 42.2 & -0.206 & -0.121 \\
\hline $4 a$ & 1.402 & 27.3 & -0.218 & -0.119 \\
\hline $4 b^{*}$ & 1.411 & 41.5 & -0.217 & -0.123 \\
\hline $4 c$ & 1.416 & 46.8 & -0.218 & -0.125 \\
\hline $4 d$ & 1.425 & 49.8 & -0.212 & -0.119 \\
\hline $4 e^{*}$ & 1.386 & 14.9 & -0.201 & -0.108 \\
\hline $4 f^{*}$ & 1.400 & 29.0 & -0.200 & -0.115 \\
\hline $4 g^{*}$ & 1.428 & 46.3 & -0.204 & -0.123 \\
\hline $4 h$ & 1.407 & 42.2 & -0.206 & -0.121 \\
\hline
\end{tabular}

a: in Angstrom c: Using TD-DFT(B3LYP)/6-31+G(d,p)

b: in degree $\quad$ *: Using PCM (DMSO). others PCM (Ethanol)

\begin{tabular}{cccccccccc}
\multicolumn{7}{c}{ Table 8 Calculated $\lambda \max (\mathrm{nm})$ dependence on XC functionals for $(\mathbf{5 a , 5 b}, \mathbf{6 a}, \mathbf{6 b})^{\text {a }}$} \\
\hline & BLYP & VSXC & О3LYP & B3LYP & B3PW91 & PBE0 & MPW1PW91 & HCTH/407 & expl. \\
\hline $5 \mathbf{a}^{*}$ & 821 & 777 & 720 & 682 & 680 & 657 & 656 & 810 & 681 \\
$\mathbf{5} \mathbf{b}^{*}$ & 984 & 582 & 832 & 774 & 771 & 734 & 734 & 961 & 729 \\
$\mathbf{6 a}$ & 605 & 582 & 565 & 552 & 548 & 535 & 536 & 597 & 548 \\
$\mathbf{6}$ & 583 & 559 & 546 & 535 & 531 & 521 & 521 & 574 & 547 \\
\hline
\end{tabular}

a: PCM-TDDFT(B3LYP)/6-31+G(d,p)/PCM-DFT(B3LYP)/6-311G(2d,2p) *: using PCM (DMSO), others using PCM (Ethanol)

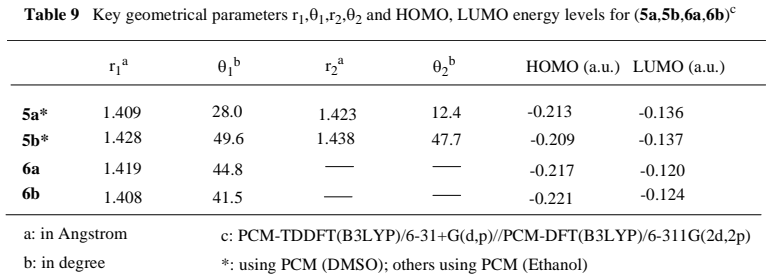

\section{Conclusion}

In this work, the UV/vis first intense electronic absorption maxima of the newly prepared maleimide derivatives were examined experimentally as well as computationally with combinations of basis sets and XC-functionals. Experimentally, these new compounds have the following UV/vis features; (1) introduction of dialkylamino group into indolizine ring contributed to the bathochromic shift of the first intense peak (2) double substitution of maleimide ring into indolizine unit (5a, 5b) realized the largest bathorchomic shift (3) benzo-annulation to indolizine ring $(\mathbf{6 a}, \mathbf{6 b})$ had little contribution to the $\lambda_{\max }$ bathochromic shift. Computationally, we employed PCM-TD-DFT(B3LYP)/6-31+G(d,p)//PCM-DFT(B3L $\mathrm{YP}) / 6-311 \mathrm{G}(2 \mathrm{~d}, 2 \mathrm{p})$ which was selected as a well-balanced level of theory from the viewpoint of cost-accuracy compromise. We reached semi-quantitative agreements between experiment and theory using TD-DFT and succeeded in theoretically reproducing the three spectroscopic features above-mentioned. Furthermore, (1) as for solvent effect on $\lambda_{\text {max }}$, indirect (geometry optimization) effect is minor while most of solvent effect is attributed to direct (TD-DFT) contribution (2) the first intense electronic absorption maximum are mainly describable with HOMO-LUMO intramolecular CT. However, we failed to obtain unequivocal systematic deviations between theoretical and experimental $\lambda_{\max }$, as in case of the TD-DFT results for cyanine dyes where the TD-DFT $\lambda_{\max }$ were systematically underevaluated [34]. The theoretical findings in the present study will greatly contribute to our further synthetic as well as theoretical research on new dyes using maleimide derivatives as key synthetic building-blocks.

\section{References}

[1] A.R.Katrizky, W.-Q Fan, Q.-L.Li and S.Bayyuk, J. Heterocycl.Chem. 26 (1989) 885.

[2] a) R.Huisgen, in 1,3-Dipolar Cycloaddition Chemistry, ed. A.Padwa, John Wiley \& Sons, , New York, Vol.1\&2 (1984); (b) E.Vedejs and F.G.West, Chem.Rev. 86 (1986) 941.

[3] a) Y.Tominaga, Matsuda Y., J. Heterocycl. Chem. 22 (1985) 937; b) Y.Tominaga, Y.Matsuda, Yuki Gousei Kagaku Kyoukaishi (J.Synth. Org. Chem. Japan) 43 (1985) 669; c) R.K.Dieter, Tetrahedron 42 (1986) 3029; d) Y.Tominaga, Yuki Gousei Kagaku Kyoukaishi (J. Synth. Org. Chem. Japan) 47 (1989) 413; e) Y.Tominaga, S.Kohra, H.Honkawa, A.Hosomi, Heterocycles 29 (1989) 1409; f) M.Kolbe, Synthesis, (1990) 171; g) H.Junjappa, H.Ila, C.V.Asokan, Tetrahedron, 1990;46:5423; h) Y.Tominaga, in Trends in Heterocyclic Chemistry 2 (1991) 43.

[4] a) Y.Tominaga, A.Ushirogouchi, Y.Matsuda and G.Kobayashi, Chem. Pharm. Bull. 32 (1984) 3384; b) Y.Tominaga, A.Ushirogouchi and Y.Matsuda, J. Heterocycl. Chem. 24 (1987) 1557; c) S.Kohra, Y.Tominaga and A.Hosomi, J. Heterocycl. Chem. 25(1988) 959

[5] Y. Tominaga, N. Yoshioka, and S. Kataoka, Heterocycles 43 (1996) 1597.

[6] Y.Shigemitsu, M.Sugimoto, K.Komiya, S.Itonaga and Y.Tominaga, Dyes and Pigments 56 (2003) 167.

[7] Y.Shigemitsu, K.Komiya, N.Mizuyama and Y.Tominaga, Dyes and Pigments 72 (2007) 271

[8] (a) S.P.Gupta, A.N.Mathur, A.N.Nagappa, D.Kumar and S.Kumaran, Eur.J.Med.Chem. 38 (2003) 867; (b) R.Bonneau, D.Collado and M.T.H.Liu, J.Photochem.Photobiol.A 161 (2003) 43; (c) T.Wiede, L.Arve, H.Prinz, H.Waldmann and H.Kessler, Bioorg. \& Med.Chem.Lett. 16 ( 2006) 59. 
[9] F.Delattre, P.Woisel, G.Surpateau, F.Cazier and P.Blach, Tetrahedron 61 (2005) 3939.

[10] V.Galasso, G.de Alti, A.Bigotto, Theor.Chim.Acta 9 (1968) 222.

[11] W.M.Paulder, J.N.Casman, J.Heterocyclic.Chem. 19 (1973) 499.

[12] J.W.Downing, J.W.Waluk, B.Stavnik, M.Tisler, B.Vereck, J.Michl, J.Org.Chem. 50 (1985) 302.

[13] E.Cané, C.Puzzarini, R.Tarroni, A.Trombetti, J.Chem.Soc.Faraday Trans. 91 (1995) 3741.

[14] R.J.Pugmire, M.J.Robins, D.M.Grant, R.K.Robins, J.Am.Chem.Soc. 93 (1971) 1887.

[15] J.W.Wiench, L.Stefaniak, G.A.Webb, J.Mol.Struct.(THEOCHEM) 605 (2002) 33.

[16] C.Antczak, B.Baubois, C.Monneret, J.C.Florent, Bioorg.Med.Chem. 9 (2001) 2843.

[17] L.M.Schopfer, J.M.Salhany, Anal.Biochem. 257 (1998) 139.

[18] C.J.Seliskar, A.P.McGlynn, J.Chem.Phys. 56 (1972) 1417.

[19] L.Harsányi, P.Császár, G.Fogarasi, G.Horváth, I.Szilágyi J.Mol.Struct.(THEOCHEM) 104 (1983) 79.

[20] T.Climent, R.González-Luque and M.Merchán, J.Phys.Chem.A 107 (2003) 6995.

[21] (a) E.Runge and E.K.U.Gross, Phys.Rev.Lett. 52 (1984) 997; (b) M.E.Casida, C.Jamorski, K.C.Casida and D.R.Salahub, J.Chem.Phys. 108(1998) 4439 (c)

M.E.Casida, In Recent Advances in Density Fucntional Methods; ed. D.P.Chong, World Scientific,Singapore, ,Vol.1 (1995).

[22] C.Adamo,G.E.Scuseria and V.Barone, J.Chem.Phys. 111 (1999) 2889.

[23] S.Hirata, M.Head-Gordon and R.J.Bartlett, J.Chem.Phys. 111 (1999) 10774.

[24] D.Jacquemin, J.Preat, V.Wathelet and E.Perpète, J.Chem.Phys. 124 (2006) 074104.

[25] D.Jacquemin, J.Preat, V.Wathelet and E.A. Perpète, J.Mol.Struct. (THEOCHEM) 731 (2005) 67.

[26] D.Jacquemin, J.Preat, M.Charlot, V.Wathelet J-M.Andrè and E.A. Perpète, J.Chem.Phys. 121 (2004) 1736.

[27] E.Perpète, V.Wathelet, J.Preat, C.Lambert and D.Jacquemin, J.Chem. Theory.Compt. 2 (2006) 434.

[28] J.Preat, D.Jacquemin and E.A. Perpète, Chem.Phys.Lett. 415 (2005) 20.

[29] A.Pezzella, L.Panzella, O.Crescenzi, A.Napolitano, S.Navaratman, R.Edge, E.J.Land, V.Barone and M.d'Lschia, J.Amer.Chem.Soc. 128 (2006) 15490

[30] A.Pezzella, L.Panzella, O.Crescenzi, A.Napolitano, S.Navaratman, R.Edge, E.J.Land, V.Barone and M.d'Lschia, J.Org.Chem. 72 (2007) 1595.

[31] M.Parac and S.Grimme, J.Phys.Chem.A 106 (2002) 6844

[32] (a) D.J.Tozer and N.C.Handy, J.Chem.Phys. 109 (1998) 10180; (b) N.C.Handy and D.J.Tozer, J.Comp.Chem. 20 (1999) 106.

[33] J.Fabian, L.Diaz, G.Seifert and T.Niehaus, J.Mol.Struct.(THEOCHEM) 594 (2002) 41.

[34] B.Chempagne, M.Guilaume and F.Zutterman, Chem.Phys.Lett. 425 (2006) 105.

[35] M.Schreiber, V.Buss and M.P.Fülscher, Phys.Chem.Chem.Phys. 3 (2001) 3906.

[36] V.Buss, M.Schreiber and M.P.Fülscher, Angew.Chem.Int.Ed. 40 (2001) 3189.

[37] D.Jacquemin, E.A. Perpète, G.Scalmani, M.Frisch, R.Kobayashi and C.Adamo, J.Chem.Phys. 126 (2007) 144105.

[38] Gaussian 03 , M. J. Frisch, G. W. Trucks, H. B. Schlegel, G. E. Scuseria, M. A. Robb, J. R. Cheeseman, V. G. Zakrzewski, J. A. Montgomery, Jr., R. E. Stratmann, J. C. Burant, S. Dapprich, J. M.
Millam, A. D. Daniels, K. N. Kudin, M. C. Strain, O. Farkas, J. Tomasi, V. Barone, M. Cossi, R. Cammi, B Mennucci, C. Pomelli, C. Adamo, S. Clifford, J. Ochterski, G. A. Petersson, P. Y. Ayala, Q. Cui, K. Morokuma, D. K. Malick, A. D. Rabuck, K. Raghavachari, J. B. Foresman, J. Cioslowski, J. V. Ortiz, A. G. Baboul, B. B. Stefanov, G. Liu, A. Liashenko, P. Piskorz, I. Komaromi, R. Gomperts, R. L. Martin, D. J. Fox, T. Keith, M. A. Al-Laham, C. Y. Peng, A. Nanayakkara, C. Gonzalez, M. Challacombe, P. M. W. Gill, B. G. Johnson, W. Chen, M. W. Wong, J. L. Andres, M. Head-Gordon, E. S. Replogle and J. A. Pople, Gaussian, Inc., Pittsburgh PA.

[39] G.Zhurko, ChemCraft ver.1.5 (2005).

[40] M.Cossi, V.Barone, J.Chem.Phys. 115 (2001) 4708.

[41] D.Jacquemin, J.Preat, and E.A. Perpète, Chem.Phys.Lett. 410 (2005) 254

[42] C.Jamorski, J.B.Foresman, C.Thilgen, H-P.Lüthi, J.Chem.Phys. 116 (2002) 8761.

[43] D.J.Tozer, R.D.Amos, N.C.Handy, B.O.Roos and L.Serrano-Andrés, Mol.Phys. 97 (1999) 859.

[44] E.A.Johnson, in UV-Vis atlas of organic compounds; H.-H.Perkampus, Ed.;VCH:Weinheim, Germany (1992) 175.

[45] W.L.F.Armarego, J.Chem.Soc. (1964) 4226. 